\section{The role of response suppression in behavioral contrast: Signaled reinforcement}

\author{
AARON J. BROWNSTEIN and RONALD \\ G. HUGHES, The University of North \\ Carolina at Greensboro, Greensboro, N.C. \\ 27412
}

After responding was maintained on multiple variable-interval schedules of reinforcement, a signaling procedure was added to one component. The signaling procedure consisted of illuminating the $k e y$, the only source of illumination in the chamber, only when responding would be reinforced. Rate of responding in the unaltered component increased. When the signaling procedure was removed, rate of responding decreased in the component in which reinforcement had never been signaled. Obtained rates of reinforcement in both components were equal throughout the experiment.

Several recent studies report that when responding in one component of two-component multiple schedules of reinforcement is suppressed, rate of responding in the other component increases, i.e., positive behavioral contrast occurs (Brownstein \& Newsom, 1970; Reynolds \& Limpo, 1968; Terrace, 1968; Weisman, 1969). Characteristic of the varied procedures used to suppress responding in these studies was that the relative rate of reinforcement did not decrease in the component in which response rate decreased. Correspondingly, the relative rate of reinforcement did not increase in the component in which response rate increased. These findings are at variance with an early formulation of behavioral contrast in which emphasis was placed on the role of relative reinforcement rates associated with the components of the multiple schedule (Reynolds, 1961a, b).

In many studies of behavioral contrast, the procedure used to suppress responding in one component also alters relative reinforcement rate in the other components. For example, Reynolds (1961a) first maintained pigeons on multiple variable-interval schedules of reinforcement and then changed the conditions in one component to time-out. The time-out consisted of eliminating all illumination in the chamber and reinforcement for any responses that might occur. Rate of responding in the unaltered component increased.

The present study was designed to clarify the roles of response suppression and relative reinforcement rate in the generation of behavioral contrast by the time-out procedure. Following exposure to multiple variable-interval schedules of reinforcement, one component was shifted to a signaled reinforcement condition. The signaled reinforcement condition consisted of eliminating all illumination in the chamber except when pecking would be reinforced. When reinforcement was available, the key was illuminated. During this condition, reinforcement availability was determined by the same variable-interval program that was used before the signal was introduced.

\section{SUBJECTS AND APPARATUS}

Four adult White Carneau pigeons, without prior experimental histories, were maintained at $80 \%$ of their free-feeding body weights.

The experimental chamber consisted of a converted ice chest similar in design to that described by Ferster \& Skinner (1957). Approximately $15 \mathrm{~g}$ of force was sufficient to operate a single translucent response key located 4 in. directly above a food hopper. The response key could be illuminated by either a red or a blue light. No houselight was present. Each response produced an audible click from a feedback relay located behind the center partition. Reinforcement consisted of $41 / 2$-sec access to grain. White noise was used to mask extraneous sounds. Standard programming equipment was employed.

\section{PROCEDURE}

All pigeons were autoshaped to peck a key, using the procedure described by Brown \& Jenkins (1968). The next three experimental sessions each consisted of 60 reinforcements of key pecking on a continuous reinforcement schedule. Half of the reinforcements were obtained for pecking when the key was transilluminated with a red light and half when the key was transilluminated with a blue light. Three sessions followed in which the red and blue illumination regularly alternated, and responses in each illumination were reinforced on a variable-interval 1-min schedule of reinforcement. Each of the next 10 sessions consisted of $106-\mathrm{min}$ cycles of a two-component multiple schedule of reinforcement. Each cycle consisted of a 3-min period during which the key light was red, followed by a 3-min period of blue illumination of the key. In each illumination, a variable-interval 2 -min schedule of reinforcement was in effect. Ten sessions followed in which the illumination during the "red" component was present only when a reinforcement was made available by the tape programmer. During the remainder of the "red" component, the key was not illuminated. No change in illumination during the blue component was effected during these sessions. Finally, 10 sessions with the original red and blue illumination conditions were run, i.e., the key was illuminated with red light throughout the red component and with blue light throughout the blue component.

\section{RESULTS}

The primary observations of the present study are the rates of responding in the blue component (the unaltered component) during the three major phases of the experiment. The data for each bird were treated in the following way. The mean rate of responding in the blue component for the 5 days preceding the introduction of the signal condition was determined. Rate of responding during each of the 10 signaled sessions was normalized with respect to the mean rate of the 5 preceding days. The curve labeled VI to SIG in Fig. 1 shows the average rates of responding for three of the four birds. Period 0 corresponds to the 5 days preceding the signal and Periods 1.10 are based on the succeeding 10 daily sessions. The rate of responding is clearly above 1.0 , the value to be expected if the signaled procedure did not affect rate of responding. The elevated rate of responding is representative of the behavior of each of the three birds used to obtain the average. The fourth bird showed no effect when the signal was introduced. Rate of responding was very close to 1.0 for the periods showed in Fig. 1. The inclusion of these data in Fig. 1 would have lowered somewhat the average rates, but they still would have been well above 1.0 . Why this

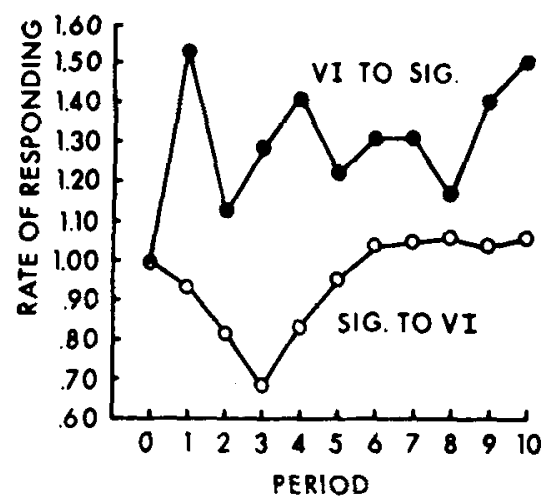

Fig. 1. Average response rates per period in unsignaled component. Rates in Periods 0.10 are normalized with respect to Period 0. (See text for further details.) 
bird did not show an increased rate is nol immediately evident. His performance prior to the introduction of the signal condition did not differ in any significant manner from that of the other birds.

The effects of the signal condition were evident during the first session with this procedure. The normalized rates of responding for the three birds whose data were used in Fig. 1 were $1.32,1.47$, and 1.79 during the first session. These values are changed only slightly if the mean of the last three sessions or just the last session preceding the introduction of the signal is used to normalize the data. Additionally, the rates obtained during the first signaled sessions are within .16 of the peak rate during Periods 1-10 for any bird. Collectively, these findings minimize the likelihood that the increased rates during the signaled condition are the result of a gradual increase in rate of responding in the blue component.

The obtained rate of reinforcement during the signaling procedure was identical to the obtained rate prior to the introduction of the signal. As was expected, all of the birds quickly responded whenever the key was transilluminated with the red light.

The effects of removing the signal procedure and reinstating the multiple variable-interval schedule is shown in the curve labeled SIG to VI in Fig. 1. The mean normalized rates of responding are presented. Rates of responding in each of the 10 sessions were normalized with respect to the mean rate of responding during the last five signaled sessions. The means are based on the three birds mentioned above. The initial effects of removing the signal are small. The maximum decline in rate for each bird was found on the third day following the removal of the signal. This gradual decline in rate of responding in the blue component was found in each of the three birds. Responding in the red component recovered to the presignal level during the first session after the signal was removed. The gradual decline in response rate in the blue component, therefore, was not correlated with a gradual recovery of responding in the red component.

\section{DISCUSSION}

The results of the present study clearly indicate that an increase in the rate of responding in one component of a multiple schedule may result from suppressing the rate of responding in the alternate component by blacking out the key. Correspondingly, when the conditions responsible for suppressing response rate are removed, a reduction in the rate of responding in the other component occurs. These instances of positive and negative behaviorai contrast, respectively, were observed in the absence of any changes in reinforcenent rate in either component.

These findings corroborate those of several recent studies that also demonstrate that a reduction in response rate in one component of a multiple schedule need not be accompanied by a reduction in relative reinforcement rate to generate positive behavioral contrast in the alternate component. Weisman (1969) suppressed responding in one component of a multiple schedule by shifting from a variable-interval schedule to a schedule in which low rates of responding were differentially reinforced (DRL). The parameters of the DRL schedule were chosen so that reinforcement rate during this component was equal to that obtained during the unaltered alternate VI component. Response rate during the VI component increased. Reynolds \& Limpo (1968) found an increase in one component of multiple DRL schedules when response rate in the alternated component was suppressed by adding an interresponse time clock. In this study, reinforcement rate in the component with the clock increased and relative reinforcement rate decreased in the component in which the response rate increased. Brownstein \& Newsom (in press) suppressed responding in one component of multiple fixed-interval schedules by adding a cue that was associated with the availability of reinforcement. A lamp was illuminated when the interval had expired. The rate of responding in the component without the cue increased. Reinforcement rates remained constant in both components. The procedure employed in the present study is most similar to that used by Reynolds and Limpo and by Brownstein and Newsom. It differs from them, however, in that the stimulus conditions employed to suppress responding are available immediately and are not dependent upon differential association with reinforcement in the context of the experiment and may even be generally independent of reinforcement contingencies.

Reynolds (1961a) found positive behavioral contrast when one component of a multiple variable-interval schedule was shifted to time-out. The procedure of the present study approximated that used by Reynolds, with the exception of the small period of time that the key was illuminated and the small number of responses that occurred with the signal procedure. The implication of the present data is that the increased response rate in the unaltered component reported by Reynolds may not result from the increase in relative reinforcement rate in that component but, rather, from the suppression of responding in the alternate component. An even closer approximation to the time-out procedure could be attained by shifting 10 a procedure involving response-independent presentations of the reinforcing stimulus in the component in which the key is not illuminated.

Although consistent with the view that a reduction in responding in one component of a multiple schedule may generate behavioral contrast (Reynolds \& Limpo, 1968; Terrace 1963a, b, 1968), the data do not reveal any simple relationship between the degree of suppression and the amount of contrast. There appears to be a slight tendency for the amount of contrast relative to baseline conditions to be inversely related to the amount of suppression (i.e., the baseline level). This relationship may be artifactual since the absolute increases do not reflect this tendency. The absence of any simple relationship between degree of suppression and amount of contrast has been discussed by Reynolds \& Limpo (1968) and explicitly studied during the development of positive behavioral contrast (Reynolds, 1968). Although adequate to generate contrast, the amount of contrast is not easily predicted from the degree of suppression. A dimension along which to order the procedures for, and the amount of, suppression is lacking.

\section{REFERENCES}

BROWN, P. L., \& JENKINS, H. M. Auto-shaping of the pigeon's key-peck. Journal of the Experimental Analysis of Behavior, 1968, 11, 1-8.

BROWNSTEIN, A. J., \& NEWSOM, C. Behavioral contrast in multiple schedules with equal reinforcement rates. Psychonomic Science $1970,18,25-26$.

FERSTER, C. B., \& SKINNER, B. F. Schedules of reinforcement. $\mathrm{New}$ York: Appleton-Century-Crofts, 1957.

REYNOLDS, G. S. Behavioral contrast. Joumal of the Experimental Analysis of Behavior, $1961 \mathrm{a}, 4,57-71$.

REYNOLDS, G. S. Relativity of response rate and reinforcement frequency in a multiple schedule. Journal of the Experimental Analysis of Behavior, 1961 b, 4, 179-184.

REYNOLDS, G. S. Positive behavioral contrast: Development within sessions. Psychonomic Science, 1968, 10, 321-322.

REYNOLDS, G. S., \& LIMPO, A. J. On some causes of behavioral contrast. Journal of the Experimental Analysis of Behavior, 1968, 11 , 543-547.

TERRACE, H. S. Discrimination training with and without "errors." Journal of the Experimental Analysis of Behavior. 1963a, 6 . $1-27$.

TERRACE, H. S. Frrorless transfer of a discrimination across two continua. Journal of the Experimental Analysis of Bchavior, 1963b, 6, 2,23-232.

TERRACE, H. S. Discrimination learning, the peak shift and bchavioral contrast. Joumal of the Experimental Analysis of Bchavior, 1968. $11,727-741$. 
WEISMAN, R. G. Some determinants of inhibitory stimulus control. Journal of the Experimental Analysis of Behavior, 1969, 12 , $443-450$.
NOTE

1. This research was supported in part by a grant from the Research Council of the University of North Carolina at Greensboro.

\section{Lysergic acid diethylamide and a novel stimulus}

\author{
EDWARD T. UYENO, Stanford Research \\ Institute, Menlo Park, Calif. 94025
}

The mean running time of rats injected with $0.016 \mathrm{mg} / \mathrm{kg}$ of lysergic acid diethylamide (LSD-25) was not significantly different from that of others, administered saline solution. However, when a novel stimulus (hurdle) was presented in the runway, the mean running time of the experimental group was significantly longer than that of the control group.

In an underwater swim test, Uyeno (1968) found that animals injected with lysergic acid diethylamide (LSD-25) took a significantly longer time to begin responding to a confronting stimulus, despite the fact that their performance involving the motor coordination was not significantly affected. To test further the effects of LSD-25 on the behavior of animals given a confronting stimulus, two runway experiments, one without and the other with an "unexpected" obstacle, were conducted.

\section{EXPERIMENT 1}

Twenty male rats of the Wistar strain weighing 190 to $210 \mathrm{~g}$, deprived of food for $22 \mathrm{~h}$, were trained to run a grey straight runway $(118 \times 12 \times 5 \mathrm{~cm})$ for a piece of food pellet. A trial was initiated by placing an animal in the startbox and by lifting the guillotine door to allow the animal to enter the alley and to run into the foodbox. Running time was recorded by starting a timer when the animal entered the alley and by stopping it when the animal entered the foodbox. After 16 distributed trials, when their running times had stabilized, they were ranked according to the mean running times of their last three trials. On the basis of their ranks, they were assigned equally to experimental and control groups to form 10 matched pairs. The experimental animals were injected intraperitoneally (i.p.) with $0.016 \mathrm{mg} / 2.5 \mathrm{ml} / \mathrm{kg}$ of LSD-25 in saline solution, whereas the control animals were administered $0.9 \%$ saline solution. Fifteen minutes after the injection, each animal, under $22 \mathrm{~h}$ of food deprivation, was given one trial in the runway, and its running time was recorded.

\section{EXPERIMENT 2}

Forty male rats, essentially similar to the ones used in the first experiment, were also trained to run the runway. They were ranked according to their running times and assigned equally to experimental and control groups in a similar manner as described previously. The experimental animals were injected (i.p.) with a dose of LSD-25, equivalent to the dose administered to the experimental animals in the first experiment, while the control animals were injected with saline. Fifteen minutes after the injection, the runway test was conducted in a similar manner as described in the first experiment, except for the introduction of a novel stimulus. A white metal hurdle, $3 \mathrm{in}$. in height, was erected in the nunway $10 \mathrm{in}$. in front of the foodbox.

\section{RESULTS AND DISCUSSION}

The data of the first experiment show that after the injection, the mean running time of the experimental group is not significantly different from that of the control group (Table 1). This finding suggests that the LSD-25-treated animals

Table 1

Analysis of Mean Running Time

\begin{tabular}{|c|c|c|c|c|c|c|}
\hline \multirow{2}{*}{$\begin{array}{l}\text { Experi- } \\
\text { ment }\end{array}$} & \multicolumn{2}{|c|}{ Before Injection } & \multicolumn{4}{|c|}{ After Injection } \\
\hline & Experimental & Control & Experimental & Control & $t$ & Significance \\
\hline \multirow{3}{*}{1} & \multicolumn{2}{|c|}{ (Sec) } & \multicolumn{2}{|c|}{$\begin{array}{c}\text { No Hurdle } \\
\text { (Sec) }\end{array}$} & & \\
\hline & 2.9 & 3.0 & 2.9 & 2.4 & 1.47 & N.S. \\
\hline & \multicolumn{6}{|c|}{ Hurdle } \\
\hline 2 & 3.3 & 3.3 & 120.8 & 85.9 & 2.21 & $5 \%$ \\
\hline
\end{tabular}

showed no apparent disruption of motor coordination. However, the results of the second experiment show that the mean running time of the experimental animals is significantly longer than that of the control animals $(t=2.21, \quad d f=1) \quad$ (Table 1$)$. Moreover, 10 experimental animals did not go over the hurdle within the time limit of $3 \mathrm{~min}$, whereas only four control animals failed. This difference is significant at the $5 \%$ level $\left(\chi^{2}=3.96, \mathrm{df}=1\right)$.

The finding that more experimental animals than control animals hesitated when the novel "unexpected" stimulus was presented is in accord with that of Uyeno (1968), who found that LSD-25-treated animals, placed in a startbox and submerged in water, showed a greater increase in starting latency than did control animals, despite no significant difference in swimming time. The present results are also consistent with those of Appel et al (1967), who trained rats to turn a wheel to escape shock and found that LSD-25 significantly increased their escape latency (i.e., the time they took to begin responding when the foot shock was presented) but did not significantly increase their rate of wheel turning. The hesitation in climbing the hurdle, the delay in emerging from the startbox, and the slowness in initiating the escape response seem to indicate that the hallucinogen disrupts the perception (Schwartz \& Cheney, 1965) of a novel obstacle and of a starting stimulus, such as the opening of the underwater startbox door and the administration of foot shock. Moreover, the compound appears to interrupt the transmission of sensory impulses at the level of the lateral geniculate (Evarts \& Marshall, 1965) and in the hippocampal system of the temporal lobe (Adey et al, 1962).

\section{REFERENCES}

ADEY, W. R., BELL, F. R., \& DENNIS, B. J. Effects of LSD-25, psilocybin, and psilocin on temporal lobe EEG pattems and learned behavior in the cat. Neurology, 1962, 12, 591-602.

APPEL, J. B., FREEDMAN, D. X., \& FILBY, Y. $M$. The effects of three psychoactive drugs on two varieties of escape behavior. Archives Internationales de Pharmacodynamie et de Thérapie, 1967, 167, 179-193.

EVARTS, E. V., \& MARSHALL, W. H. The effects of lysergic acid diethylamide on the excitability cycle of the lateral geniculate. Transactions of the American Neurological Association, 1965, 80, 58-60.

SCHWARTZ, A. S., \& CHENEY, C. Retinal effects of high doses of LSD in the cat. Experimental Neurology, 1965, 13, 273-282.

UYENO, E. T. Hallucinogenic compounds and swimming response. Journal of Pharmacology \& Experimental Therapeutics, 1968, 159, 216-221.

NOTE

1. This work was supported by Grant MH-16124 from the National Institutes of Health, U. S. Public Health Service. 